\title{
Collaboration of Art and Science for Decreasing Stigma and Mental Disorders Associated with COVID-19
}

\author{
Fereshteh Moshfegh ${ }^{1}$, Farshad Khosraviani ${ }^{2}$, Bita Asgari $^{3}$, Ebrahim Boluki ${ }^{1, *}$ \\ ${ }^{1}$ Department of Dentistry, New Vision University, Tbilisi, Georgia \\ ${ }^{2}$ DDS, UCLA School of Dentistry, Los Angeles, CA, USA \\ ${ }^{3}$ DDS, MPH student, National University, San Diego, CA, USA \\ "Corresponding Author: Ebrahim Boluki, Department of Dentistry, New Vision University, Tbilisi, Georgia
}

Received date: 07 July 2021; Accepted date: 14 July 2021; Published date: 18 July 2021

Citation: Moshfegh F, Khosraviani F, Asgari B, Boluki E. Collaboration of Art and Science for Decreasing Stigma and Mental Disorders Associated with COVID-19. J Comm Med and Pub Health Rep 2(6): https://doi.org/10.38207/jcmphr20210089

Copyright: () 2021 Ebrahim Boluki. This is an open-access article distributed under the terms of the Creative Commons Attribution License, which permits unrestricted use, distribution, and reproduction in any medium, provided the original author and source are credited.

\begin{abstract}
The ongoing pandemic SARS-CoV-2 (also known as 2019-nCoV and COVID-19) viral infection is spreading worldwide, posing a universal hazard with the onset and spread of acute respiratory disease. In addition to medical complications, mental health impact is one of the most important challenges facing recovered patients from COVID-19, known as stigmatization. social stigmatization can arise from fear of persons who are different and the fear of disease. The mutual cooperation of science and art in the form of scientific discipline can play an effective role in promoting the culture of the society to reduce the destructive effects of this phenomenon.
\end{abstract}

Keywords: Stigmatization, SARS-CoV-2, COVID-19, Infectious disease, Health education, Communication design.

\section{Introduction}

The globe is facing a new public health catastrophe with the rise and expansion of acute respiratory infection[1]. This challenge was the trigger of one of the most serious clusters of coronavirus disease2019 (COVID-19). The COVID-19 first arose in December 2019 and then rapidly expanded over the world [2].

Initially, the new virus was called 2019-nCoV. On January 7, 2019 the World Health Organization (WHO) stated the term "Coronavirus disease 2019 (COVID-19)" as the name of this novel disease. Subsequently, on 11 February 2020, the International Committee on Taxonomy of Viruses (ICTV) named the novel virus "severe acute respiratory syndrome coronavirus 2 (SARS-CoV-2) . The virus was given this name since it is genetically similar to the coronavirus that began the 2003 SARS outbreak (SARS-CoVs). regardless of their similarity, the two viruses are not the same $[3,4]$.

Coronavirus subdivided into four genera alpha, beta, gamma, and delta $(\alpha, \beta, \gamma, \delta)$ that are widespread in nature [5-7]. SARS-CoV-2 belongs to the $\beta$-coronavirus family, a big class of viruses that are widespread in nature. They are a vast family of single-stranded ribonucleic acid viruses (+ssRNA) that can be isolated from a variety of animal species [8, 9]. In humans, Coronavirus illness can

\section{History of stigma}

Stigmatization has a long tradition and its association with disease is not a new phenomenon. In ancient Greece, "stigma" was a brand to mark slaves or criminals [17] have a range from the common cold to more serious diseases such as SARS-CoV, the Middle East respiratory syndrome, coronavirus (MERS-CoV), and SARS-CoV-2, which are all members of the genus Beta coronavirus $[\mathbf{1 0}, \mathbf{1 1}]$ The natural reservoirs of these viruses are birds and bats $[12,13]$.

Currently, scientists around the globe work to understand as much as possible about the SARS-CoV-2. COVID-19 information, including transmission mechanisms, the clinical aspect of the disease, novel diagnostics, and prevention and treatment options, is steadily evolving [9, 14]. However, this phenomenon and its consequences are certainly not limited to medical disease. Like SARS, COVID-19 has a side effect of conventional contact, which is associated with social and mental stigma and discrimination. social stigmatization can arise from fear of persons who are different and the fear of disease $[15,16]$. Although the effects of the stigmatization on COVID-19 have not yet been studied systematically [17]

In this study, we investigate stigmatization in the past and contemporary era. Subsequently, the collaboration between art and science that leads to improving the harmful effects of stigma will be explained.

Like humans, animals are always evaluating the creatures around them. Many species at various levels of taxonomic exhibit behavioral avoidance and social rejection. Chimpanzees provide many examples of social exclusion [18]. Some animal species are 
more dependent on visual signs, such as changes in appearance or behavior to detect infection [19]. Chimpanzees are one such species, and it has been discovered that they participate in behavioral avoidance of unhealthy conspecifics [18]. Sticklebacks, a species of small fish, stay away from other sticklebacks if those individuals release signs indicating parasite infestation [20]. Bullfrog tadpoles selectively eschew swimming close to tadpoles affected with infectious intestinal parasites; infected spiny lobsters have been avoided by the healthy ones [21].

Throughout history, stigma related to epidemic and pandemic diseases has often hampered treatment and prevention and forced additional suffering on patient individuals and their loved ones [22]. Erving Goffman in his book pointed out, the infrastructure of stigma research as a scientific discipline can explain how stigmatized persons are facing the challenge [23]. One of the most famous people known to have experienced stigmata was St. Francis of Assisi. He was the recognized leader of the young men of the town, although he was always a very prominent and well-known person for his charity to the people in need. After a serious medical

\section{Stigma in the modern age}

In the modern age, stigmatizing persons suffering from infectious diseases serves no purpose [28]. Stigma does not enhance the capability of current civilizations to withstand contagious diseases, it leads to an obstacle between the patient and the rest of the society, who impede them from acting on their instinctive desire to seek curative. They also act as catalysts for failures in protecting public health [29]. If people feel stigmatized, whether externally or internally, occurring negative behaviors is unavoidable including (a) prevention from seeking care, which results in impediment to the control of the outbreak, (b) fear of disclosing their disease to avoid prejudice from the entire groups or communities, (c) erupting into violence against the stigmatized group, infringement of their human rights and social exclusion and severe economic consequences [30, 31].

Stigma brings disastrous consequences for individuals and communities. Even after recovering people from an illness completely, the stigma imposed by society's culture can affect an individual's views, norms, and values. Such behaviors and attitudes lead to reducing the quality of life and mental health problems [32, 33]. Studies have revealed that not only affected people but also their family members are influenced by discriminatory behaviors. Such circumstances lead to limiting/ decreasing their access to care, loss of social status, and in extreme cases, disowning/denying them [34]. All of these factors can increase stress, anxiety, and depression in people involved with stigma [35]. This results in hesitation to facilitate care for ill family members, owing to concern of disease revealing to the community. People with mental health problems are encountered various challenges including refusal of returning to the problem at the age of 21 , his friends found him "in a trance, a permanently altered man." After these events, he devoted the remainder of his life serve to the sick and died at the age of 45 [24]. Many diseases have been characterized by social stigmatization in patients with transmissible diseases throughout history. For example, tuberculosis, leprosy, plague, and human immunodeficiency virus (HIV) were stigmatized throughout the last several centuries [22, 24]. A study has revealed that about one-third of people would not wear a washed jacket that had previously been used by an HIV-positive individuals and none of them would drink water from a washed and sterilized glass that had previously been used by such a person [25]. Observations from the SARS and influenza A (H1N1) virus outbreaks are similar [18]. According to this concept, in one study, approximately $20 \%$ of respondents held that SARS patients remained infectious a year and a half after recovery [26]. Also similar to such post-recovery social behaviors were also widely observed for people who had contracted the H1N1 virus [27].

profession after treatment, rejecting the hire of the person, marriage, and education $[34,36]$. Such xenophobic sentiments about Covid-19 might induce people to avoid or refuse others, even if they are not in danger of transmitting the virus [37].

There are well-documented studies that the AIDS stigma has been harmful to the health of those who have suffered from the disease and has had a role in restricting public health and medical attempts to contain the problem $[25,38]$. It has been noted that how the physical layout or space within a facility can mitigate the experience of stigma. For instance, a pharmacist who was involved in the training on relieving stigma became aware that their clients who were suffering from HIV use a dedicated window for getting their drugs. After the intervention, all customers utilize the same window at present [39].

Stigma in the context of virus disease is disconcerting. Violence behaviors such as harassment, rejection, and abandonment, not allowed to return home, ruining homes of people with Ebola, and individuals who were in contact with them have been reported in Uganda between 2000 and 2001. Regardless of surviving some of them, stigmatization is continuous. Stigmatization among quarantined people during the Ebola epidemic in Liberia caused exclusion from their ethnic and tribal groups. Such stigma may lead to concealing/ covering diseases and rejecting the help among nonEbola illnesses [40]. In another study, Chang and colleagues pointed out that the concern of SARS has resulted in a significant decrease in the number of people asking for medical care [41]. Negative consequences of having cancer-related stigma including cheerlessness, perturbation, and the demoralization among patients 
with cancer lead to delaying seeking medical care and concealing their disease [42, 43]. Have been confirmed by many psychoneuroimmunology studies that mental state (stress level, depression, worrying, prolonged grief, and negative thinking) can impact the immune function and can weaken it [44, 45]. A weakened immune system leads to faster disease progression and/or poorer health outcomes. Stigma and discrimination play a stronger effect in the relationship between physician empathy and the immune system. Yang et al. [46] found that the role of physician'

\section{Collaboration of science and art}

COVID-19's social stigma has received little attention in research investigations [47]. Timely and effective measures are necessary to be developed and implemented for research on the stigmatization of infection disease, such that we can improve our insight and identify the inevitable consequences of such stigmatization.

WHO stated how communicating about severe SARS-CoV-2 is critical in supporting people to take effective action to help overcome the disease and to avoid fear and stigma [49] Furthermore, the Central for Disease Control and Prevention (CDC) noted that stigmatized groups may be exposed to social avoidance or rejection, refusal of healthcare, education, housing or employment, and physical violence [50]. Stigmatization is so important that researchers were cautious in naming this virus to avoid any stigma as far as the director-general of the WHO announced, "Our team had to get a name that did not refer to a geographical area, a species, a person, or a group of people so that it be pronounceable and interdependent to the disease." [51].

One of the biggest challenges is the misconception of the illness. This causes stigmatization for infected people that are emerging from inaccurate information created by widespread media coverage. As a result, in the present time, the management of emerging infectious diseases and public health would necessitate that we strengthen our capacity and knowledge to reduce the stigma connected with those diseases. Based on this concept, a recent study by the Korea Centers for Disease Control and Prevention suggested that recovered COVID-19 patients who test positive again are not infectious. They were no longer capable of diagnosing live virus in cell culture, indicating that the positive diagnostic tests were sampling dead virus particles [52]. Given this, the virus may be thought to be dead or so weak that it cannot infect another host. Also, CDC mentioned that "Someone who has followed the standard principles of quarantine or has been discharged from isolation does not involve the hazard of transmission of SARS-CoV- 2 to others" [53]. This can lead to the acceptance of fully recovered patients and a barrier to labeling these patients in society. Also, Neutralized antibodies that exist in the blood of people who have completely recovered, can potentially inactive the virus. These individuals can donate plasma, the component of blood that contains antibodies, to empathy has a negative impact on the correlation of patients' stigma and Patients' stigma was negatively correlated with their NK cells activity (Natural killer cells)

Stigma is difficult to overcome. This will be especially true in a post-Covid-19 environment. It is critical to remember that the COVID-19 outbreak is related to stigma [47]. According to Nature, do not identify COVID-19 with specific groups of individuals or places, and underline that "viruses do not distinguish; everyone is at peril." [48].

COVID-19 patients causing the acceleration of recovery $[\mathbf{5 4}, \mathbf{5 5}]$. So, we have to be aware of the fact that the recovered patients who have recovered completely not only cannot transmit the COVID-19 but also can save the life of infected people by donating plasma. Furthermore, they are actually symbolling of hope that they have had COVID-19 and have come out.

According to WHO, health education is defined as a combination of planned learning experiences meant to help individuals and societies enhance their health by developing their knowledge and influencing their behaviors and views [56, 57]. A little Italian town is an example of this strategy. They resolved to investigate the difficulties of COVID-19-related disinformation and social stigma by health education. They enlisted the help of epidemiologists and respiratory infectious disease experts to arrange live online activities for the public. These events were held on the council website and social networks (e.g., Facebook and WhatsApp groups), and they were well received, with several questions (over 60 per session) answered and addressed. In summary, a small number of messages of concern about the epidemic have been sent to municipal representatives [16]. Creative and critical thinking lead to the increased power of discovery and innovation. Artistic activity plays an important role in the advancement of Science. Neil's Bohr's model is an example of concurrent modifications in literature and the arts, such as Cubism

[58]. Medical students at the University of California, Irvine School of Medicine were utilizing masterworks by Van Gogh, Rembrandt, Kandinsky, and Da Vinci and fine arts not only improve observation skills but also receive better skills in emotional recognition and growth of empathy $[\mathbf{5 8}, \mathbf{5 9}]$.

Because of lacking enough information about COVID-19 among Somali citizens, Nujuum decides to use her arts for raising awareness about how deadly the disease is and how to avoid it across Somalia. Also, there has been a negotiation between EU Delegation in Somalia and young Somali artists to give further and useful information about the outbreak. She shares crucial information about COVID-19 via her talent and art to raise awareness of a wide range of people including educated, not educated, and even deaf or blind people [60]. 
Visual thinking is known as problem-solving ability which is a special feature of artists that can be useful for decreasing stigmatization via training and multi-level community interventions such as spreading information about disease transmission, skillbuilding, and so on $[\mathbf{4 0 , 6 1 ]}$. We believe that the more extensive use

\section{Conclusion}

The psychological effect of social rejection is one of the most important issues that individuals after recovery from the serious COVID-19 disease is facing. Stigmatization not only causes the spread of fear, anxiety, and even panic but also increases the risk of psychological distress and burnout. Health education is one of the critical ways to address stigmatization. Artists take a prominent role in coping with the COVID-19-related stigma and discrimination

\section{References}

1. Simone CB, Friedberg JS, Glatstein E, Stevenson JP, Sterman DH, et al. (2012) Photodynamic therapy for the treatment of non-small cell lung cancer. Journal of thoracic disease. 4(1): 6375 .

2. Moshfegh F, Khosraviani F, Farpour N, Boluki E. Controlling the Spread of SARS-CoV-2 via Sniffer Dogs. Alexandria Journal of Veterinary Sciences. 2021;69(1): 168-178.

3. Moshfegh F, Khosraviani F, Moghaddasi N, Limoodi SFSJ, Boluki E (2021) Antiviral optical techniques as a possible novel approach to COVID-19 treatment. Journal of Innovative Optical Health Sciences. (14)3: 2130002.

4. Chawla D, Chirla D, Dalwai S, Deorari AK, Ganatra A, et al (2020) Perinatal-neonatal management of COVID-19 infection-guidelines of the Federation of Obstetric and Gynaecological Societies of India (FOGSI), National Neonatology Forum of India (NNF), and Indian Academy of Pediatrics (IAP). Indian pediatrics. 57(6): 536-548.

5. Woo PC, Lau SK, Lam CS, Lau CC, Tsang AK, et al. (2012) Discovery of seven novel Mammalian and avian coronaviruses in the genus deltacoronavirus supports bat coronaviruses as the gene source of alphacoronavirus and betacoronavirus and avian coronaviruses as the gene source of gammacoronavirus and deltacoronavirus. Journal of virology. 86(7): 3995-4008.

6. Su S ,Wong G, Shi W, Liu J, Lai ACK, et al. (2016) Epidemiology, genetic recombination, and pathogenesis of coronaviruses. Trends in microbiology. 24(6): 490-502.

7. Cui J, Li F, Shi Z-L (2019) Origin and evolution of pathogenic coronaviruses. Nature reviews Microbiology. 17(3): 181-192.

8. Moshfegh F, Ezzati A, Ezzati A, Bahraini M, Boluki E, et al. (2021) Therapeutic and Diagnostic Approaches for SARS-CoV2. Voice of the Publisher. 7(2): 63-79. of communication design and visual arts training in medical education would help to reduce stigma and demystify COVID-19. The cooperation of experts in various fields including artists and scientists can eliminate or decrease the detrimental effects of the Corona phenomenon from the international community.

using techniques and strategies to simplify the complexity of present science. International and multi-sector collaboration between artists and various biological scientists will cause the creation of educational achievements of visual communication. Changing our attitude and behavior happens afterward. Which in turn, increasing the awareness of community members will create a behavior-based culture with patients and individuals who have recovered.

9. Cascella M, Rajnik M, Cuomo A, Dulebohn SC, Di Napoli R (2020) Features, evaluation and treatment coronavirus (COVID19). StatPearls Publishing.

10. Benvenuto D, Giovanetti M, Ciccozzi A, Spoto S, Angeletti S, et al. (2020) The 2019-new coronavirus epidemic: evidence for virus evolution. Journal of medical virology. 92(4): 455-459.

11. Ma C, Su S, Wang J, Wei L, Du L, et al. (2020) From SARSCoV to SARS-CoV-2: safety and broad-spectrum are important for coronavirus vaccine development. Microbes and Infection. 22(6-7): 245-253.

12. Corman VM, Baldwin HJ, Tateno AF, Zerbinati RM, Annan A, et al. (2015) Evidence for an ancestral association of human coronavirus 229E with bats. Journal of virology. 89(23): 1185870.

13. Anand K, Karade S, Sen S, Gupta R (2020) SARS-CoV-2: Camazotz's Curse. Med J Armed Forces India. 76(2): 136-141.

14. Yao H, Chen J-H, Xu Y-F (2020) Patients with mental health disorders in the COVID-19 epidemic. The Lancet Psychiatry. 7(4): e21.

15. Des Jarlais DC, Galea S, Tracy M, Tross S, Vlahov D (2006) Stigmatization of newly emerging infectious diseases: AIDS and SARS. American journal of public health. 96(3): 561-7.

16. Sotgiu G, Carta G, Suelzu L, Carta D, Migliori GB (2020) How to demystify COVID-19 and reduce social stigma. Int J Tuberc Lung Dis. 24(6): 640-642.

17. Carta MG, Perra A, Atzeni M, D’Oca S, Moro MF, et al. (2017) An evolutionary approach to mania studying Sardinian immigrants to Argentina. Brazilian Journal of Psychiatry. 39(2): $147-53$.

18. Oaten M, Stevenson RJ, Case TI (2011) Disease avoidance as a functional basis for stigmatization. Philos Trans R Soc Lond B Biol Sci. 366(1583): 3433-52. 
19. Thomas C, Morris SM, Clark D (2004) Place of death: preferences among cancer patients and their carers. Soc Sci Med. 58(12): 2431-44.

20. Kurzban R, Leary MR (2001) Evolutionary origins of stigmatization: the functions of social exclusion. Psychol Bull. 127(2): 187-208.

21. Behringer DC, Butler MJ, Shields JD (2006) Avoidance of disease by social lobsters. Nature. 441(7092): 421.

22. Zacks S, Beavers K, Theodore D, Dougherty K, Batey B, et al. (2006) Social stigmatization and hepatitis C virus infection. J Clin Gastroenterol. 40(3): 220-4.

23. Goffman E. Stigma: Notes on the management of spoiled identity: Simon and Schuster; 2009.

24. LIFSCHUTZ JE (1957) Hysterical stigmatization. Am J Psychiatry. 114(6): 527-31.

25. Herek GM, Capitanio JP, Widaman KF (2002) HIV-related stigma and knowledge in the United States: prevalence and trends, 1991-1999. American journal of public health. 92(3): $371-7$.

26. Lau JT, Yang X, Wong E, Tsui H (2006) Prevalence and factors associated with social avoidance of recovered SARS patients in the Hong Kong general population. Health education research. 21(5): 662-673.

27. Perry P, Donini-Lenhoff F (2010) Stigmatization complicates infectious disease management. AMA Journal of Ethics. 12(3): 225-30.

28. Smith RA, Hughes D (2014) Infectious disease stigmas: Maladaptive in modern society. Commun stud. 65(2): 132-138.

29. Williams J, Gonzalez-Medina D, Le Q (2011) Infectious diseases and social stigma. Applied Innovations and Technologies. 4(1): 58-70.

30. Yamaguchi S, Mino Y, Uddin S (2011) Strategies and future attempts to reduce stigmatization and increase awareness of mental health problems among young people: a narrative review of educational interventions. Psychiatry and clin Neurosci. 65(5): 405-15.

31. Ten Have H. Encyclopedia of global bioethics: Springer International Publishing Switzerland; 2016.

32. Organization WH. Mental health and work: Impact, issues and good practices. Geneva: World Health Organization. 2000.

33. Kapil R. Four Ways Culture Impacts Mental Health 2019

34. van der Land J, Mitchell EM, van de Berg S, Leimane I (2018) Measuring secondary stigmas among TB-affected workers and families. TB Stigma.

35. Stangl AL, Earnshaw VA, Logie CH, van Brakel W, Simbayi LC, et al. (2019) The Health Stigma and Discrimination Framework: a global, crosscutting framework to inform research, intervention development, and policy on health-related stigmas. BMC medicine. 17(1): 31.
36. Link B, Struening EL, Neese-Todd S, Asmussen S, Phelan JC (2002) The Consequences of Stigma for the Self-Esteem of People With Mental Illnesses. Psychiatric services (Washington, DC). 52(12): 1621-6.

37. Prevention CfDCa. Know the facts about coronavirus disease 2019. CDC. April 3, 2020.

38. Parker R, Aggleton P (2003) HIV and AIDS-related stigma and discrimination: a conceptual framework and implications for action. Soc Sci Med. 57(1): 13-24

39. Nyblade L, Stockton MA, Giger K, Bond V, Ekstrand ML, et al. (2019) Stigma in health facilities: why it matters and how we can change it. BMC medicine. 17(1): 1-15.

40. Brooks SK, Webster RK, Smith LE, Woodland L, Wessely S, et al. (2020) The psychological impact of quarantine and how to reduce it: rapid review of the evidence. The Lancet. 395(10227): 912-920.

41. Chang H-J, Huang N, Lee C-H, Hsu Y-J, Hsieh C-J, et al. (2004) The impact of the SARS epidemic on the utilization of medical services: SARS and the fear of SARS. American journal of public health. 94(4): 562-4

42. Fujisawa D, Hagiwara N (2015) Cancer stigma and its health consequences. Current Breast Cancer Reports. 7(3): 143-150.

43. Gonzalez BD, Jim HS, Cessna JM, Small BJ, Sutton SK, et al. (2015) Concealment of lung cancer diagnosis: prevalence and correlates. Psycho-Oncology. 24(12): 1774-83.

44. Weiss R, Vittinghoff E, Fang MC, Cimino JE, Chasteen KA, et al. (2017) Associations of Physician Empathy with Patient Anxiety and Ratings of Communication in Hospital Admission Encounters. Journal of hospital medicine. 12(10): 805-10.

45. Moraes LJ, Miranda MB, Loures LF, Mainieri AG, Mármora CHC (2018) A systematic review of psychoneuroimmunologybased interventions. Psychology, health \& medicine. 23(6): 635652 .

46. Yang N, Cao Y, Li X, Li S, Yan H, et al. (2018) Mediating effects of patients' stigma and self-efficacy on relationships between doctors' empathy abilities and patients' cellular immunity in male breast cancer patients. Medical science monitor. 24: 3978-3986.

47. Li W, Yang Y, Ng CH, Zhang L, Zhang Q, et al. (2020) Global imperative to combat stigma associated with the coronavirus disease 2019 pandemic. Psychological Medicine. 1-2.

48. Stop the coronavirus stigma now. Nature. 2020. 580(7802): 165.

49. (WHO) WHO. A guide to preventing and addressing social stigma associated with COVID-19: World Healthcare Organization team (WHO); 24 February 2020.

50. Prevention CfDCa. Reducing Stigma: (CDC); March 30, 2020.

51. Bruns DP, Kraguljac NV, Bruns TR (2020) COVID-19: Facts, Cultural Considerations, and Risk of Stigmatization. Journal of Transcultural Nursing. 31(4): 326-332. 
52. Prevention KCfDCa. Findings from investigation and analysis of re-positive cases. Korea Centers for Disease Control and Prevention 19 May 2020.

53. Prevention CfDCa. Stop the Spread of Rumors April 3, 2020.

54. Mukherjee AP (2020) Hypothesis: Immunotherapy by Selective Convalescent Blood Engineering to stifle diseases like COVID19.

55. Dzik S (2020) COVID-19 Convalescent Plasma: Now Is the Time for Better Science. Transfusion Medicine Reviews. 34(3): 141-144.

56. Heijnders M, Van Der Meij S (2006) The fight against stigma: an overview of stigma-reduction strategies and interventions. Psychology, health \& medicine. 11(3): 353-63.

57. Control CfD. Guidelines for effective school health education to prevent the spread of AIDS: US Department of Health and Human Services, Public Health Service, Centers ...; 1988.
58. Braund M, Reiss MJ (2019) The 'great divide': how the arts contribute to science and science education. Canadian Journal of Science, Mathematics and Technology Education. 19(3): 219236.

59. Shapiro J, Rucker L, Beck J (2006) Training the clinical eye and mind: using the arts to develop medical students' observational and pattern recognition skills. Medical education. 40(3): 263-8.

60. Mukami M. Somali artists use art to spread COVID-19 awareness 2020 [Available from: https://www.aa.com.tr/en/africa/somali-artists-use-art-to-spreadcovid-19-awareness/1890554.

61. Davtyan M, Brown B, Folayan MO (2014) Addressing Ebolarelated stigma: lessons learned from HIV/AIDS. Global health action. 7(1): 26058 